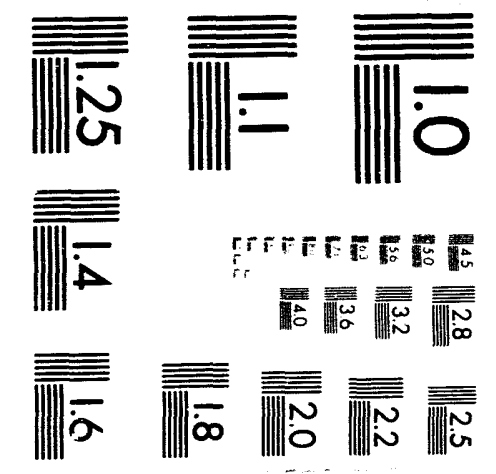



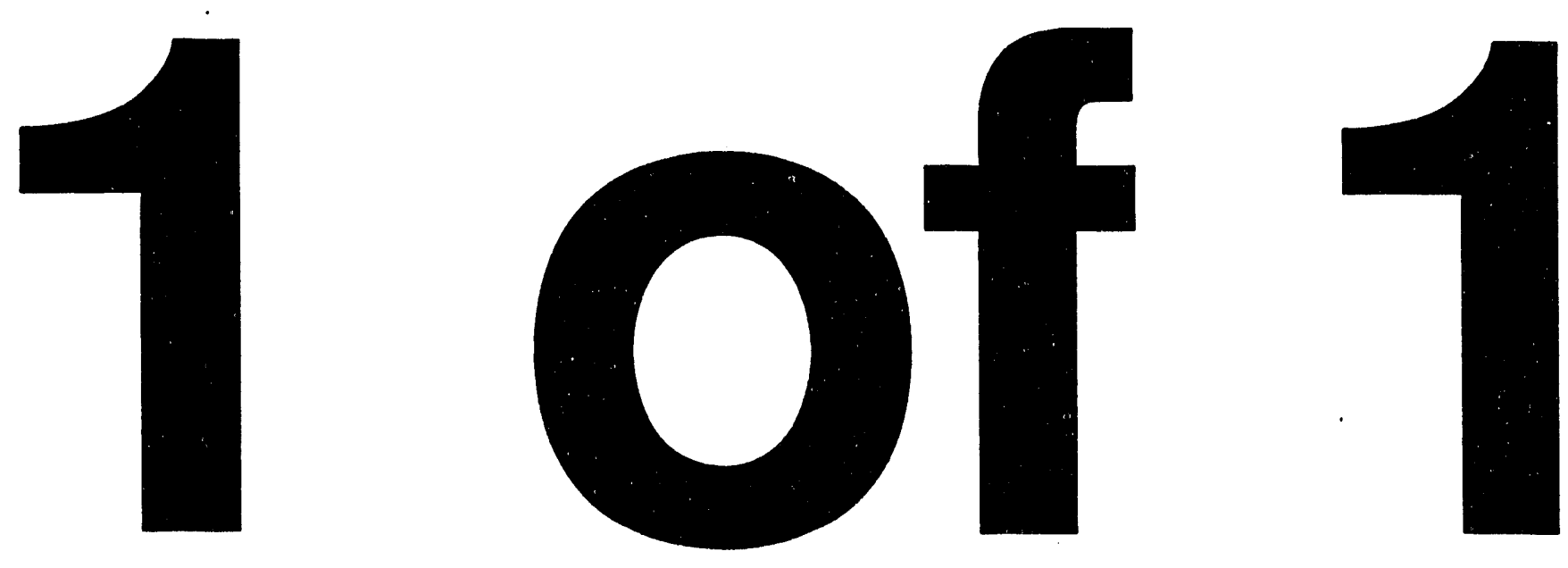


\section{CCNF $9.31108+10$}

LA-UR- 23-4218

FIRST RESULTS FROM THE LOS ALAMOS PLASMA SOURCE ION IMPLANTATION EXPERIMENT

AUTHORS:

D. J. REJ, J. R. CONRAD, R. J. FAEHL, R. J. GRIBBLE, I. HENINS, N. HORSWILL, P. KODALI, M. NASTASI, W. A. REASS, M. SHAMIM, K. SRIDHARAN, J. TESMER, K. C. WALTER, B. P. WOOD

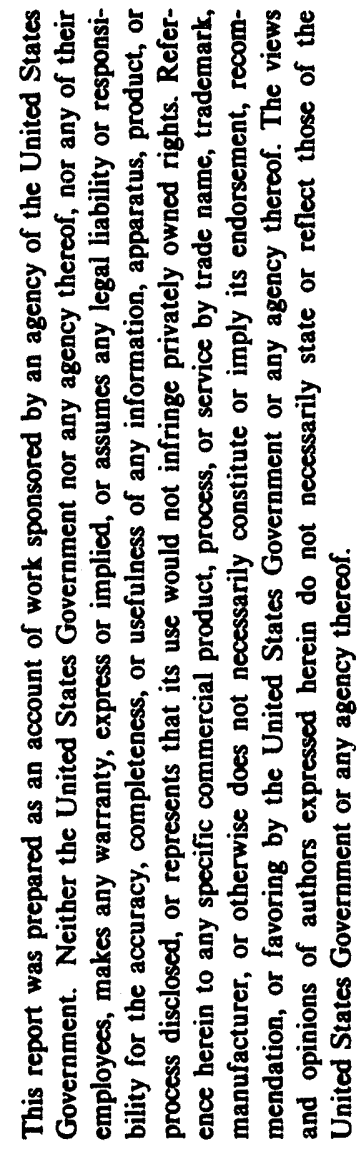

1993 Fall Meeting of the Materials Research Society Boston, MA

November 29 - December 3, 1993

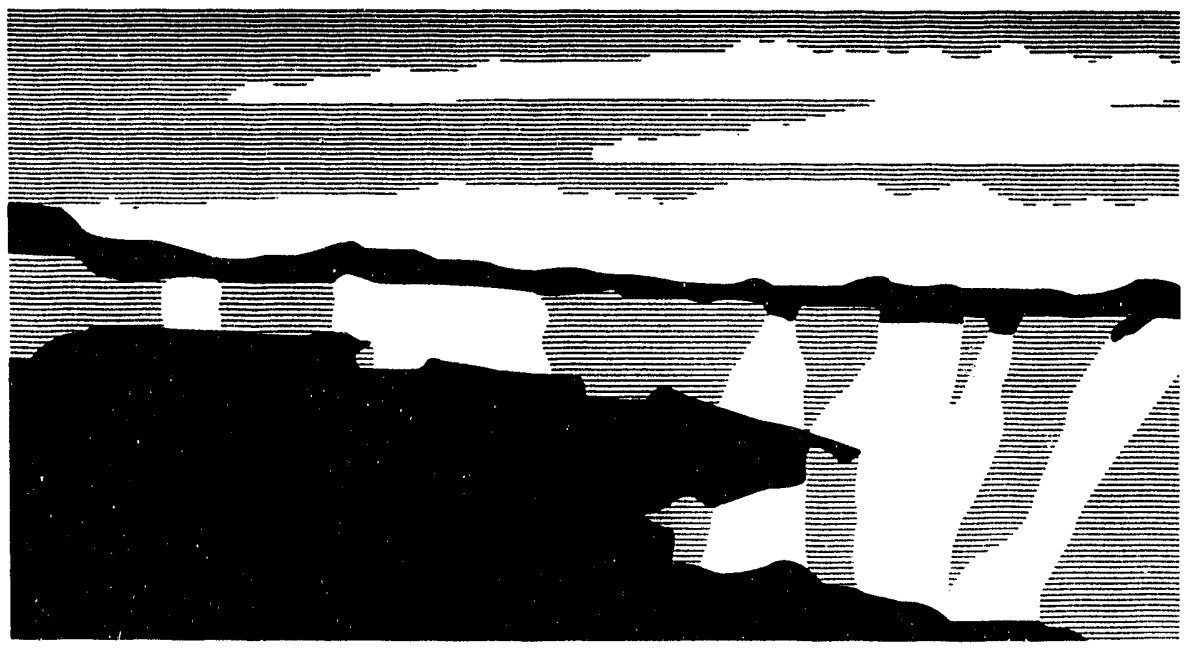

Los Alamos National Laboratory, an affirmative action/equal opportunity emplóyer, is operated by the University of California for the U.S. Department of Energy under contract W-7405-ENG-36. By acceptance of this article, the publisher recognizes that the U.S. Government retains a nonexclusive, royalty-free license to publish or reproduce the published form of this contribution, or to allow others to do so, for U.S. Government purposes. The Los Alamos National Laboratory requests that the publisher identify this article as work pertormed under the auspices of the U.S. Department of Energy. 


\title{
FIRST RESULTS FROM THE LOS ALAMOS PLASMA SOURCE ION IMPLANTATION EXPERIMENT
}

\author{
D. J. REJ,* J. R. CONRAD, ${ }^{* *}$ R. J. FAEHL,* R. J. GRIBBLE, ${ }^{*}$ I. HENINS, \\ N. HORSWILL, ${ }^{*}$ P. KODALI, $*$ M. NASTASI, $*$ W. A. REASS, ${ }^{*}$ M. SHAMIM, $* *$ \\ K. SRIDHARAN, ${ }^{* *}$ J. TESMER, ${ }^{*}$ K. C. WALTER, ${ }^{*}$ B. P. WOOD, ${ }^{*}$ \\ *Los Alamos National Laboratory, MS- E526, Los Alamos, NM 87545 \\ ** Univ. Wisconsin, Nuclear Engineering and Applied Physics Dept., Madison, WI 53706
}

\begin{abstract}
A new facility is operational at Los Alamos to examine plasma source ion implantation on a large scale. Large workpieces can be treated in a 1.5-m-diameter, 4.6-m-long plasma vacuum chamber. Primary emphasis is directed towards improving tribological properties of metal surfaces. First experiments have been performed at $40 \mathrm{kV}$ with nitrogen plasmas. Both coupons and manufactured components, with surface areas up to $4 \mathrm{~m}^{2}$, have been processed. Composition and surface hardness of implanted materials are evaluated. Implant conformality and dose uniformity into practical geometries are estimated with multidimensional particle-incell computations of plasma electron and ion dynamics, and Monte Carlo simulations of ion transport in solids.
\end{abstract}

\section{INTRODUCTION}

Plasma source ion implantation ${ }^{1}$ (PSII) is an innovative technique to generate high dose implants into complicated shapes in a simple, fast, efficient, and cost-effective manner. A negative high-voltage pulse is applied to a workpiece which is immersed in a plasma. Plasma ions are accelerated by the electrical potential and are implanted perpendicularly into all exposed surfaces of the workpiece. A new facility to study large-scale applications of PSII has become operational this year at Los Alamos National Laboratory. The cylindrical, stainless steel processing chamber is $1.5-\mathrm{m}$ diameter by $4.6-\mathrm{m}$ long. Plasmas are produced by a capacitively-coupled $13.56-\mathrm{Mhz}$ rf discharge. Experiments are conducted in relatively low density $\left(10^{14}-10^{15} \mathrm{~m}^{-3}\right)$ plasmas produced in background fills of 0.3 nitorr or less. Ions are accelerated by a high-voltage pulser capable of producing $125-\mathrm{kV}, 60 \mathrm{j}$-A pulses with a $4 \%$ duty cycle. Further details about the hardware may be found in Rer. 2 ,

\section{EXPERIMENTAL}

First experiments were performed with nitrogen plasmas isud se intive sy fow ion energies. Typical high-voltage pulse characteristics were: peak voltage $\approx 40 \mathrm{k} \psi$, neak current $\approx 45 \mathrm{~A}$, pulsewidth $\approx 20 \mu \mathrm{s}$, voltage risetime $\approx 5 \mu \mathrm{s}$, repetition rate $\approx 50 \%, 4 \mathrm{z}, \mathrm{Tr} . \mathrm{N} \mathrm{N}_{2}$ working gas (99.99\% pure) pressure was typically between 0.1 and 0.2 mtcr t. While the base pressure (believed to be mostly $\mathrm{H}_{2} \mathrm{O}$ ) was $1 \times 10^{-5}$ torr. A variety aluminum, chromium, silicon, steel, and titanium, were imp'cincu. Both coupons and manufactured components, with surface areas up to $4 \mathrm{~m}^{2}$, were processed.

The most comprehensive tests were performed on implanted M2 tool steel. Unheattreated samples $(20 \mathrm{HRC})$ were mechanically polished to an arithmetic surface roughness of approximately $100 \mathrm{~nm}$. The retained dose was determined by resonant non-Rutherford 
backscattering ${ }^{4}$ of an $8.9 \mathrm{MeV}, 20-\mathrm{nA}, \mathrm{He}^{+}$beam. At this $\mathrm{He}^{+}$energy, the resonant scattering cross section for nitrogen is 75-times higher than the Rutherford cross section, resulting in an enhanced sensitivity for determining nitrogen concentrations. Implanted concentration profiles were measured with a scanning Auger microprobe. An $\mathrm{Ar}^{+}$gun was used to sputter atoms from the sample surface to make compositional measurements as a function of aepth. A raster size of approximately $1 \times 1 \mathrm{~mm}$ was used, and the analysis was carried out for a few minutes after the implanted species concentration dropped below the detection limit of the instrument. Composition as a function of sputtering time was deemed as the most appropriate representation of the data since the sputter rate could change with composition at an unknown rate. However, the depth of the sputter crater after the Auger analysis was measured with a surface profilometer to estimate the approximate depth of the implanted layer, assuming a linear sputtering rate.

Surface mechanical properties were evaluated with a Knoop microhardness tester at loads ranging from 2 to 10 grams. For these tests, a fine oblong diamond-tipped indentor was impressed upon the sample at a specified load. The length of the long diagonal of the indentation on the sample was measured under a microscope equipped with electronic cursors and digitally correlated to the ASTM Knoop hardness number. The Knoop microhardness test was particularly advantageous because the large major diagonal-to-depth ratio $(30: 1)$ provided for a high resolution measurement in hardness as a function of depth. At least ten measurements were made at each load to obtain statistically-significant values.

\section{RESULTS AND DISCUSSION}

An implanted ion dose $D_{i}$ between 1 and $1.5 \times 10^{17} \mathrm{~cm}^{-2}$ into the $\mathrm{M} 2$ steel was estimated from the total time-integrated modulator current and workpiece area, correcting for the secondary electron emission. Since the plasma consisted of unknown proportions of $\mathrm{N}_{2}{ }^{+}$and $\mathrm{N}^{+}$, the actual implanted nitrogen dose was between 1 and $2 \mathrm{D}_{\mathrm{i}}$. Nitrogen could not be detected by Rutherford backscattering of $2 \mathrm{MeV} \mathrm{He}^{+}$because of the relatively low $\mathrm{N}$ scattering cross section compared to those of the constituent elements in the steel. However, the resonant non-Rutherford back scattering of $8.9 \mathrm{MeV} H e$ ions did reveal the presence of nitrogen in the implanted samples (Fig. 1), with a retained dose of $(1.0 \pm 0.1) \times 10^{17} \mathrm{~cm}^{-2}$. In addition, oxygen was detected in both the implanted (with dose $1.1 \times 10^{17} \mathrm{~cm}^{-2}$ and unimplanted (with dose $0.6 \times 10^{17} \mathrm{~cm}^{-2}$ ) samples.

Results of Auger analysis for the unimplanted and implanted M2 steel samples are shown in Figures $2 \mathrm{a}$ and $\mathrm{b}$, respectively. The sputter crater depth after 13 minutes was $300 \pm 100$ $\mathrm{nm}$. The relatively large uncertainty was due to the sample surface roughness. The nitrogen profile exhibits a broadened, subsurface maximum, characteristic of a sputter-limited distribution and the non-monoenergetic energy spectrum of PSII.

The implanted nitrogen dose profiles were also estimated using the Profile Code. ${ }^{5} \mathrm{~A}$ variety of implanted doses $D_{i}$ ranging between 1 and $5 \times 10^{17} \mathrm{~cm}^{-2}$ were considered. Ions entered normal to the workpiece surface at ion energies, $E_{i}=20$ and $40 \mathrm{keV}$, corresponding to the $\mathrm{E}_{\mathrm{i}}$ of $\mathrm{N}_{2}{ }^{+}$and $\mathrm{N}^{+}$in the experiment. The results are plotted in Fig. 3. The retained doses $D_{r}$ varied from $0.8 \times 10^{17} \mathrm{~cm}^{-2}$ to a sputter-limited value of $1.7 \times 10^{17} \mathrm{~cm}^{-2}$ for $E_{i}=20$ $\mathrm{keV}$. There is qualitative agreement between the simulation and the Auger profile for doses 
$D_{i}=1.0$ to $1.5 \times 10^{17} \mathrm{~cm}^{-2}$. It is difficult to obtain a quantitative comparison at this time, however, because of the uncertainties in the plasma composition and the sputter depth measurements.

The analyses indicate the incorporation of oxygen during implantation. The Auger depth profiles indicate a thicker oxide layer after implantation, while resonant $\mathrm{He}^{+}$ scattering indicates an $80 \%$ increase in total concentration. Since sample temperatures remained relatively low $\left(<150^{\circ} \mathrm{C}\right)$ during implantation, it is speculated that the increased oxygen content is due to recoil mixing of an oxide surface layer that consisted of both the native layer plus that adsorbed from background gas impurities in the PSII chamber.

A modest improvement in microhardness is observed in the implanted samples, as illustrated by the data in Fig. 4 . Error bars denote the standard deviations from at least 10 measurements at different locations on each sample. The improvement in microhardness becomes more apparent at low loads since the indentation depth approaches the implanted layer thickness. However, even at the lowest load employed (2 grams), the indentation depth is large enough to include substrate effects; thus, the improvement in hardness in the near surface regions is underestimated. The scatter in hardness data increases at the lower loads because of inherently larger

Fig. 3: Computed nitrogen concentrations: (a) $E_{i}=20 \mathrm{keV}, \quad D_{i}=1 \times 1017 \mathrm{~cm}^{-2}, D_{r}=$ $0.77 \times 10^{17} \mathrm{~cm}^{-2}$; (b) $\mathrm{E}_{\mathrm{i}}=20 \mathrm{keV}, \mathrm{D}_{\mathrm{i}}=2 \times 10^{17}$ $\mathrm{cm}^{-2}, D_{\mathrm{r}}=1.34 \times 1017 \mathrm{~cm}^{-2}$; (c) $E_{i}=20 \mathrm{keV}$, $\mathrm{D}_{\mathrm{i}}=3 \times 10^{17} \mathrm{~cm}^{-2}, \mathrm{D}_{\mathrm{r}}=1.7 \times 10^{16} \mathrm{~cm}^{-2} ;$ (d) $E_{i}=20 \mathrm{keV}, D_{i}=5 \times 1017 \mathrm{~cm}^{-2}, D_{r}=$ $1.8 \times 10^{16} \mathrm{~cm}^{-2} ;$ (e) $\mathrm{E}_{\mathrm{j}}=40 \mathrm{keV}, \mathrm{D}_{\mathrm{i}}=1 \times 10^{17}$ $\mathrm{cm}^{-2}, \mathrm{D}_{\mathrm{r}}=0.86 \times 1017 \mathrm{~cm}^{-2}$.

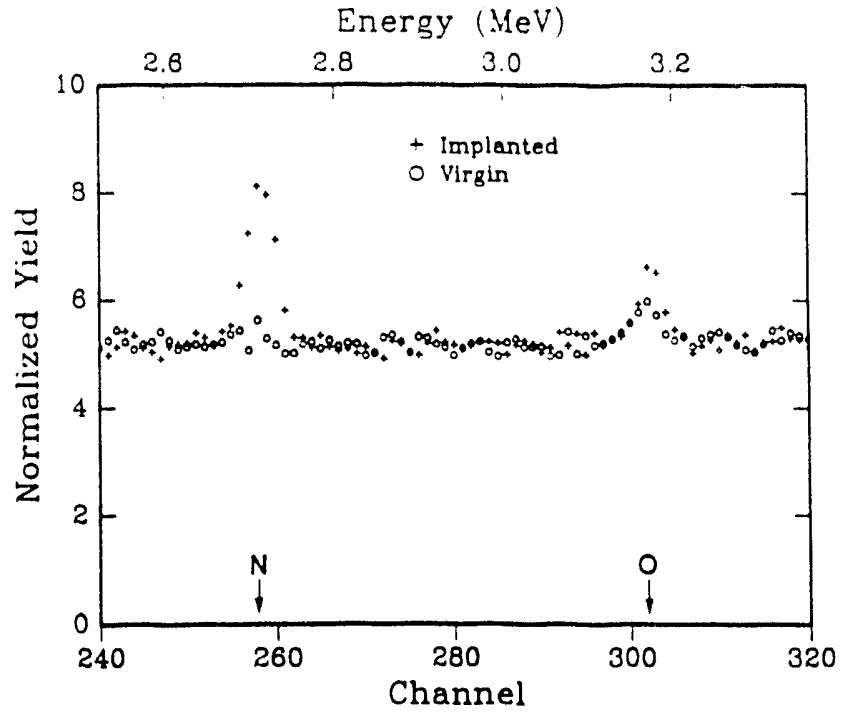

Fig. 1: Resonant non-Rutherford backscattering spectra for $\mathrm{N}$ and $\mathrm{O}$ in unimplanted $(0)$ and implanted $(+) \mathrm{M} 2$ steel. Incident $\mathrm{He}+$ energy was $8.9 \mathrm{MeV}$.
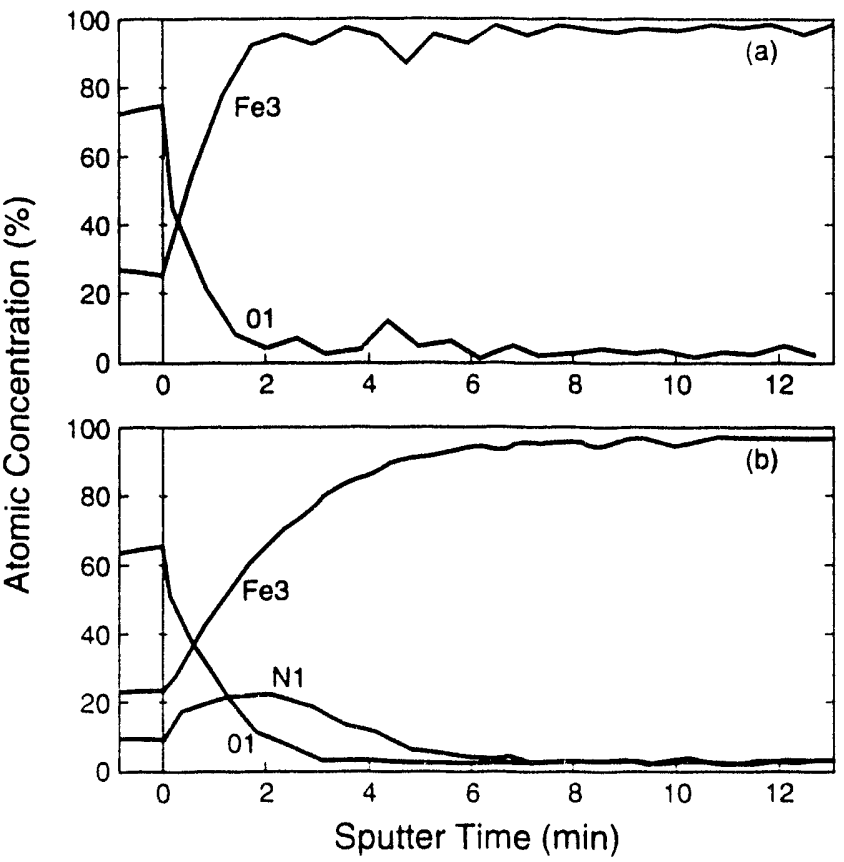

Fig. 2: Concentration depth profiles from Auger spectroscopy on (a) unimplanted and (b) implanted M2 steel.

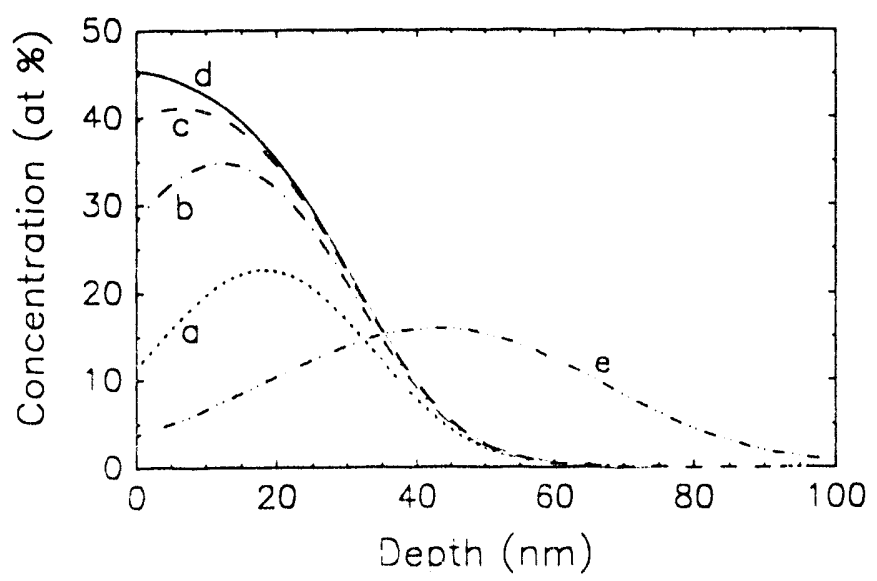


uncertainties associated with the measurement of smaller indents, the second phase carbide distribution in the M2 steel, and the surface roughness. The principal hardening mechanism is speculated to be due to nitride formation with iron and the alloying elements present in the steel. Previous work at U. Wisconsin on a variety of tool steels has indicated that the improvement in hardness noted in Fig. 4 is accompanied by a factor of two reduction in friction and can translate into a significant improvement in tool life in a number of applications. ${ }^{6}$

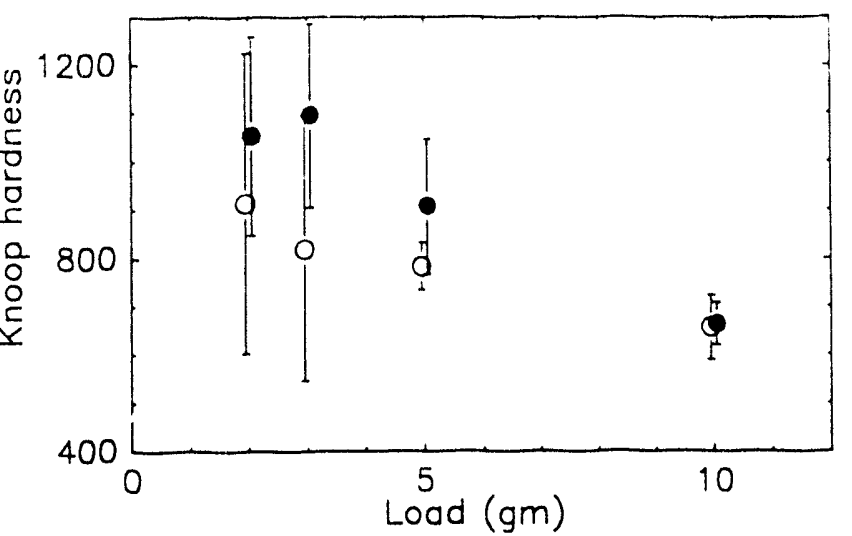

Fig. 4: Measured Surface microhardness for unimplanted (o) and implanted $(\bullet)$ M2 steel.

An important feature of PSII is that the process is not line of sight. Implant profiles are uniform over the workpiece area as long as the thickness $s$ of the plasma sheath, through which ions are accelerated, remains small compared to the workpiece feature size. For certain applications, this condition may not be easily attained. During the quasi-steady, space-chargelimited current phase, the plasma acts as a resistive load to the high-voltage pulsed power supply. This load impedance $Z_{p}$ for an expanding planar sheath is obtained by combining Child-Langmuir Equation with Ohm's law,

$$
\mathrm{Z}_{\mathrm{p}}=\left[9 / 4 \varepsilon_{\mathrm{o}}\right][\mathrm{M} / 2 \mathrm{e}]^{1 / 2}\left\{\mathrm{~s}^{2} /\left[\mathrm{A}(\gamma+1) \mathrm{V}^{1 / 2}\right]\right\} \quad,
$$

where $\mathrm{M}$ is the ion mass, $\mathrm{A}$ is the workpiece area, $\gamma$ is the coefficient for secondary electron emission, and $\mathrm{V}$ is the magnitude of the applied voltage. Present-day high-voltage switch technology can drive load impedances of approximately $100 \Omega$ or more. For a specified voltage and workpiece area, this limit corresponds to a minimum sheath dimension (or plasma density). For $A=5 \mathrm{~m}^{2}, \gamma=7, \mathrm{Z}_{\mathrm{p}}=100 \Omega$, and $\mathrm{V}=-100 \mathrm{kV}$, relatively large sheaths, $\mathrm{s}$ $\geq 0.1 \mathrm{~m}$, are mandatory for an $\mathrm{N}_{2}{ }^{+}$plasma and planar geometry.

Implant uniformity in PSII has been assessed by simulations with a fully-electromagnetic,

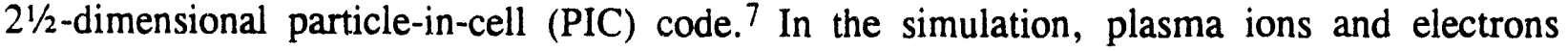
move under combined electric and magnetic fields $\mathbf{E}$ and $\mathbf{B}$ obtained by solving Maxwell's equations. All three components of momenta, $\mathbf{E}$, and $\mathbf{B}$ are followed in time and on the fixed mesh. Spatial variations are limited to two dimensions. The technique is self-consistent because the particle currents are used as sources for solving Maxwell's equations, while the E and $\mathbf{B}$ which result from that solution are used as the forces to move the particles. Spatial resolution ranges from 5 to $15 \mathrm{~mm}$, and the typical time step is $3 \mathrm{ps}$.

Simulations have been performed for a $100-\mathrm{kV} \mathrm{N}_{2}{ }^{+}$implant into an elongated workpiece geometry corresponding to the Pierce punch that was PSII treated and reported in Ref. 1. The voltage risetime is $100 \mathrm{~ns}$. The shape of the sheath is most clearly seen in the spatial distribution of electrons. At an early time $(t=0.27 \mu \mathrm{s}$, Fig. 5a), the cylindrical shape of the punch is still roughly retained. Much later $(t=1.3 \mu \mathrm{s}$, Fig. $5 \mathrm{~b})$, the sheath expansion is almost spherical and any shape information about the punch has been "washed out." Ions are always being accelerated toward the part. in the direction normal to the sheath. 


\section{Electrons}

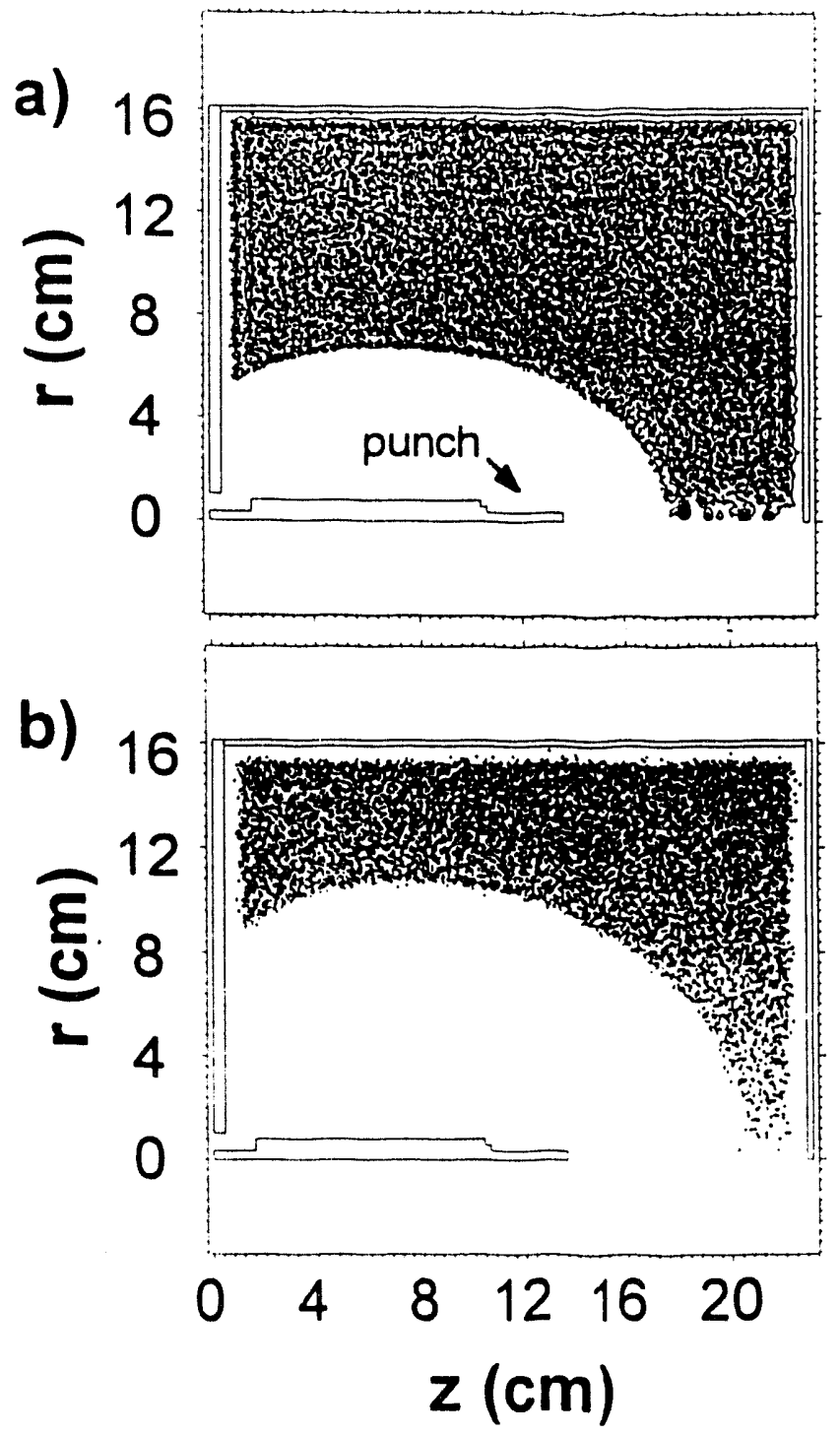

\section{lons}

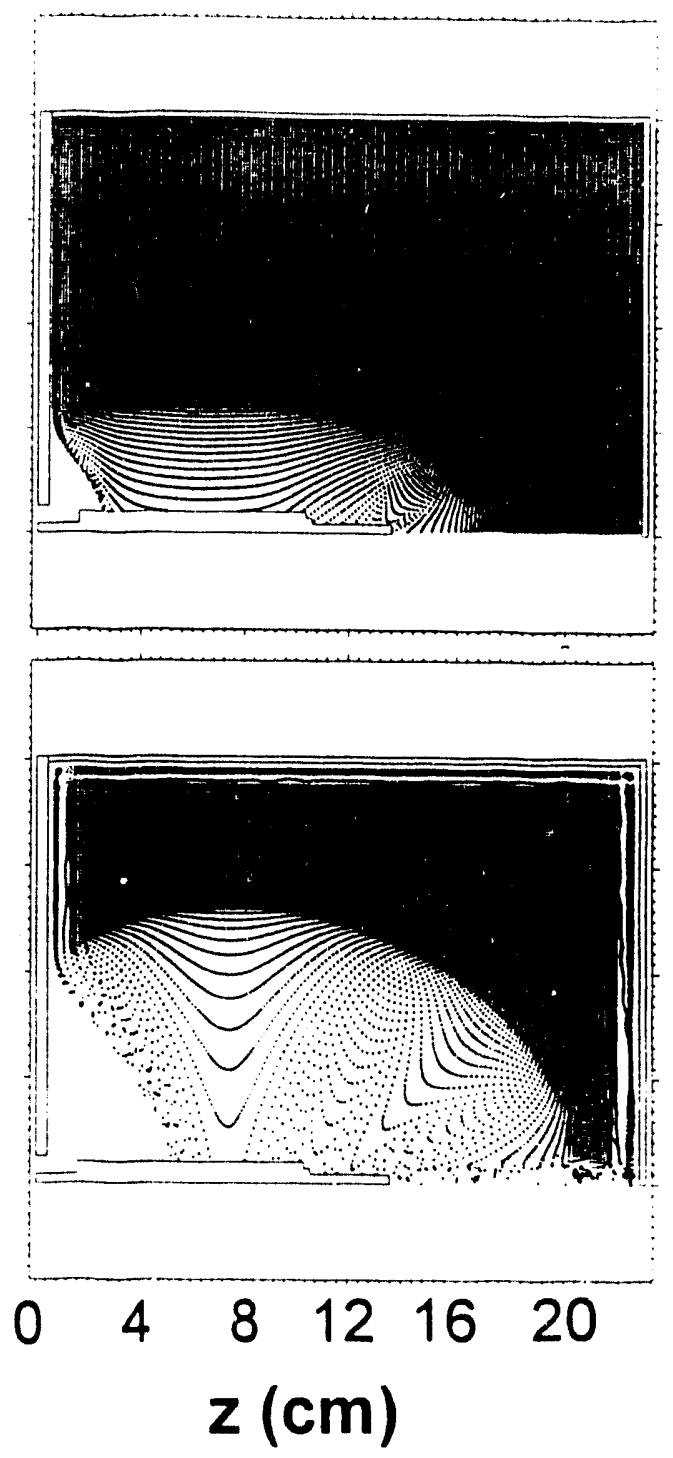

Fig. 5: Particle-in-cell simulation of PSII into Pierce punch. Electron and ion positions are plotted at (a) $t=0.3$ and (b) $t=1.3 \mu$ s into pulse.

Ion trajectories through the sheath are computed with the PIC code to determine the angle of incident $\theta$ and implanted dose $D_{i}$ to the workpiece during a pulse. The distribution of $\theta$ and relative $D_{i}$ across the flank surface of the punch $(r=5.7 \mathrm{~mm})$, averaged over a $1.5 \mu \mathrm{s}$ pulse, are plotted in Fig. 6a and b, respectively. Variations in the local ion current density cause the implanted dose to vary by $34 \%$. Retained dose profiles computed with the Profile Code are also plotted in Fig. 6b, for cases where the implanted doses at the tip of the punch were 2 and $5 \times 10^{17} \mathrm{~cm}^{-2}$. Near the tip of the punch, the increase in $\theta$ results in larger sputtering losses; consequently variations in the retained dose are estimated to be as large as $67 \%$. Therefore, if s cannot be kept sufficiently small, extra fixturing or multiple workpiece configurations are required to eliminate edge field phenomenon that affect implant uniformity. 


\section{SUMMARY}

A large scale plasma source ion implantation cevice is operational at Los Alamos. Initial implants have been performed with relatively low-energy nitrogen ions. Measured implant doses and depth profiles are consistent with MonteCarlo estimates. Mixing of native and impurity oxide layers is also evident. Improvements in surface hardness of ionimplanted M2 steel is observed. Though PSII is intrinsically a non-line-of-sight process, conformality is only assured when the feature size is small when compared to the plasma sheath dimension. This constraint is not always easily satisfied in large-scale systems. Future experiments will be directed at higher accelerating voltages (up to $100 \mathrm{kV}$ ), repetition rates ( 1 to $2 \mathrm{kHz}$ ), and with alternative ion sources such as carbon.

\section{ACKNOWLEDGMENTS}

Technical assistance from C. Evans, R.P. Fetherston, J. Garcia, M. Hollander, R. Romero, D. Roybal, and B. Vigil is gratefully acknowledged. This research is supported by the U.S. Dept. of Energy Defense Programs Technology Transfer Initiative through a cooperative research and development agreement with the
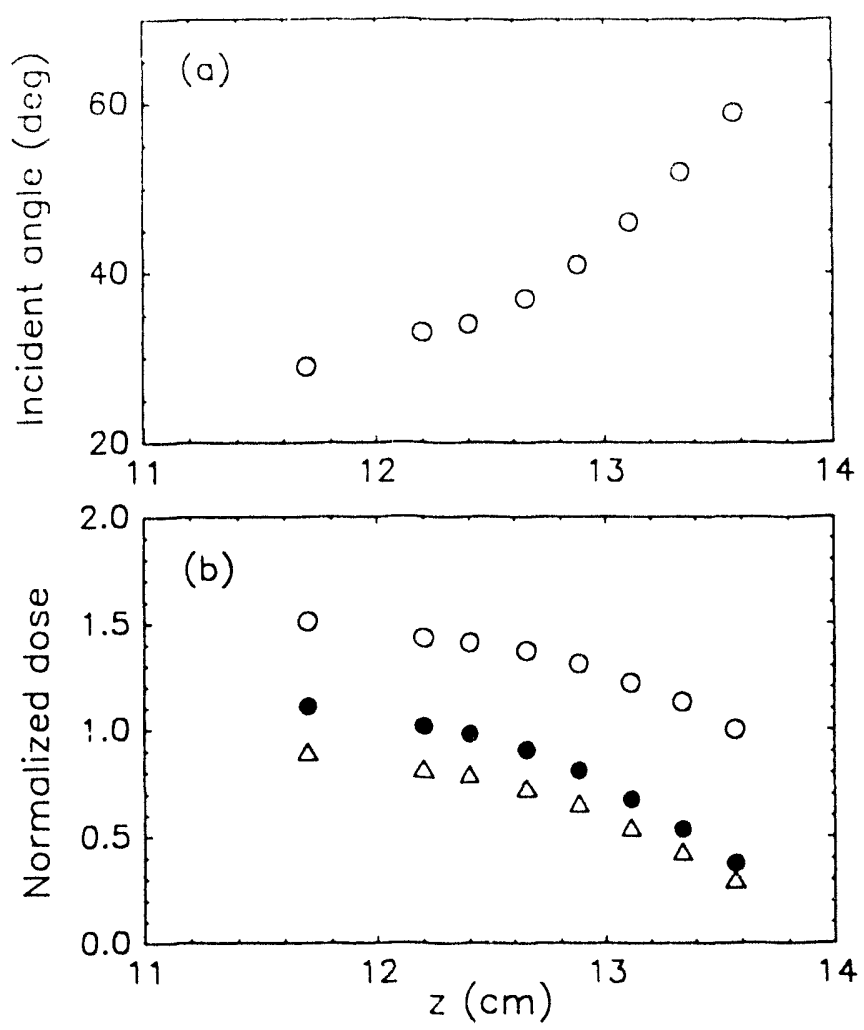

Fig. 6: (a) Average incident angle of implanted $\mathrm{N}$ ions along flank surface of Pierce punch as computed with the PIC simulation. Punch geometry is shown in Fig. 5. (b) Normalized implanted dose (o) from PIC simulation, and retained dose computed with the Profile Code for an implanted dose: $D_{\mathrm{io}}=2 \times 10^{11} \mathrm{~cm}^{-2}$ $(\bullet)$, and $5 \times 10^{17} \mathrm{~cm}^{-2}(\Delta)$ near the edge of the punch. All three dose profiles are normalized to $\mathrm{D}_{\mathrm{io}}$.

\section{REFERENCES:}

1. J.R. Conrad et al., J. Applied Physics 62, pp. $4591-4596$ (1987).

2. B. P. Wood et al., Proc. 1992 Fall Meeting of the Materials Research Society; Symposium A, MRS Symposium Series Vol. 279 (MRS, Pittsburgh, PA, 1993), p.345.

3. B. P. Wood et al., J. Vac. Sci. Tech. (in press).

4. L. A. Foster et al., Nucl. Instr. Meth. in Phys. Res. B79, 454 (1993).

5. Available from Implant Sciences Corp., Wakefield, MA 01880.

6. Materials Technology 8, 89 (1993.)

7. R. J. Faehl et al., J. Vac. Sci. Tech. (in press). 

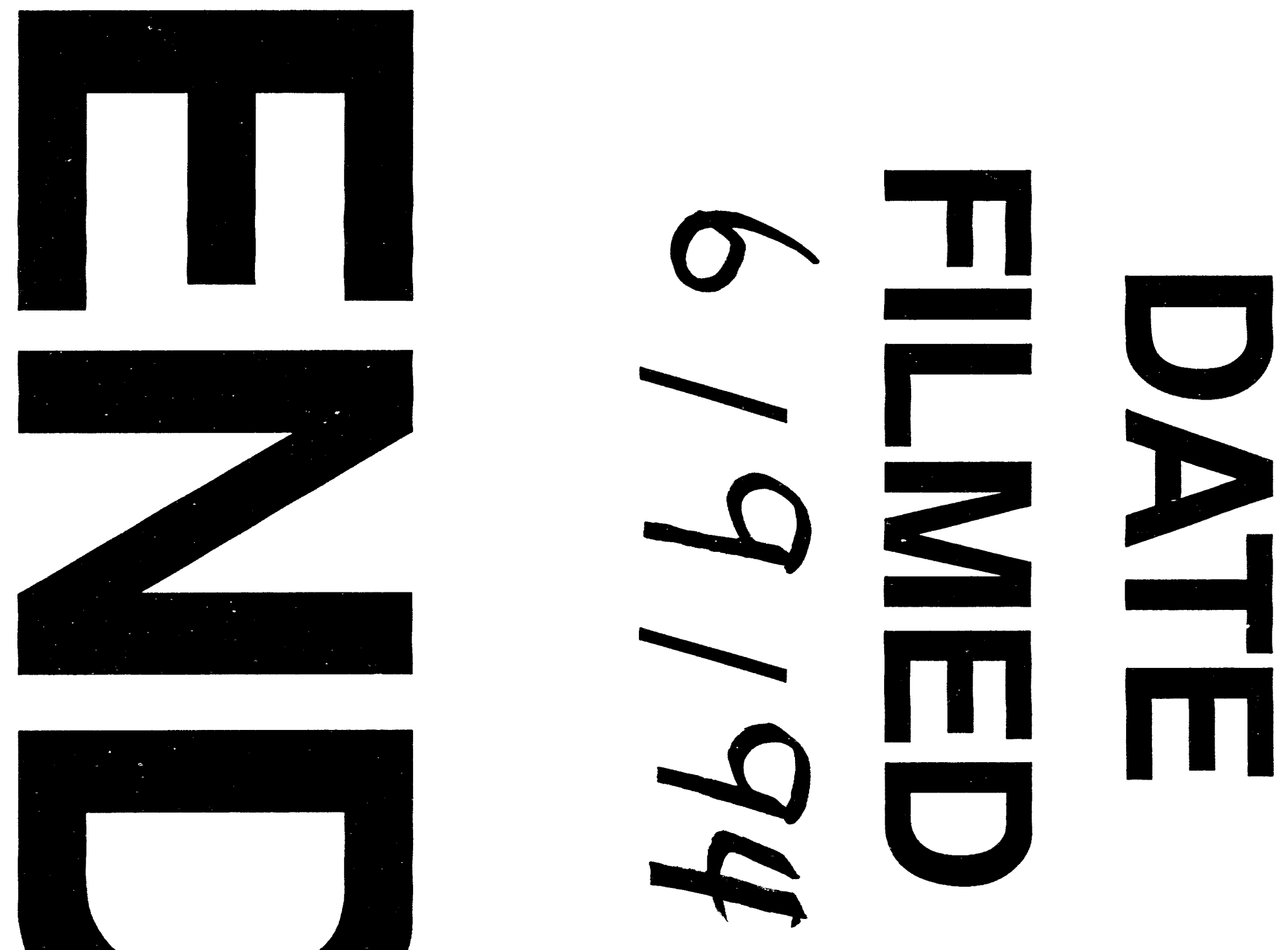
